\title{
Vorwärts in die 1930er Jahre?
}

\author{
STEPHAN SCHULMEISTER
}

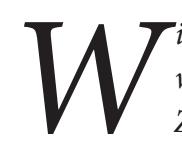

ie wird sich die große Krise weiter entwickeln? Rekapitulieren wir zunächst den bisherigen Verlauf.

Zwischen 2003 und 2007 treibt ein Spekulationsboom den Wert von Aktien, Immobilien und Rohstoffen in die Höhe, dem Bullenmarkt folgt ein Bärenmarkt. Die gleichzeitige Entwertung der drei Vermögensarten verursacht einen Wirtschaftseinbruch. Die manisch-depressiven Schwankungen der ("freiesten“) Finanzmärkte können von den Eliten nicht als systemische Hauptursache der Krise wahrgenommen werden.

Also beschränkt man sich auf Symptombekämpfung durch Bankenund Konjunkturpakete, die finanzkapitalistische Spielanlage bleibt unangetastet. Wirtschaftseinbruch und Rettungsmaßnahmen erhöhen die Staatsverschuldung. Dies ermöglicht ein neues Spiel, die Spekulation auf den Staatsbankrott. Die Zinsen von Anleihen der „schlechten“ Länder von Griechenland bis Italien - steigen immer mehr, die "guten" Länder profitieren davon, besonders Deutschland.

Die neoliberale Deutungshoheit ist wiederhergestellt: Schuldig sind „die Griechen“ und die anderen Südländer, „die Märkte“ sollen sie durch hohe Zinsen disziplinieren. Generell muss der (Sozial)Staat sparen, der Fiskalpakt erhöht den Druck. Je radikaler Griechenland, Portugal, Spanien und Italien Arbeitslosengelder, Renten und Löhne kürzen, desto stärker schrumpft ihre Wirtschaft und desto stärker steigt die Staatsverschuldung.

Ein Rückblick erleichtert den Ausblick: Ein Spekulationsboom führt 1929 zum Börsenkrach samt Rezession, das Budgetdefizit steigt, die Sparpolitik treibt die Wirtschaft in eine Depression. Die Spannungen in und zwischen den Ländern nehmen zu, Sündenböcke werden gesucht, Antisemitismus und Protektionismus breiten sich aus.

Ausbreitungsgeschwindigkeit und Intensität der gegenwärtigen Krise sind viel geringer als Anfang der 1930er Jahre. So verzögert der Sozialstaat - sein Ausbau war ein Ergebnis der Weltwirtschaftskrise - die Abwärtsspirale. Auch ist die in Zeitungen und Büchern geschürte Stimmung gegen „die Griechen" oder „die Türken“ harmlos im Vergleich zu den Angriffen auf „die Juden“" (allerdings sehen die Aufwiegler damals wie heute deutsche Interessen bedroht). Dennoch: Die gegenwärtige Krise entfaltet sich nach der gleichen Logik wie jene vor 80 Jahren. Damals wie heute verwenden die Eliten die gleiche Navigationskarte: Eine marktreligiöse Wirtschaftstheorie legitimiert Finanzalchemie, diese verursacht einen Einbruch der Wirtschaft und damit hohe Haushaltsdefizite, die Krise wird in eine Schuldenkrise des (Sozial)Staats umgedeutet, die Sparpolitik führt in eine Abwärtsspirale, die Feindseligkeit zwischen den Ländern nimmt zu. Dieser Prozess setzte in Griechenland ein und hat sich über Irland, Portugal, Spanien nach Italien ausgebreitet. In wenigen Monaten wird der Rest Europas in eine Rezession schlittern. In einer solchen Lage braucht es Politikerinnen und Politiker, die den Mut haben, den Rat der Mainstream-Ökonomen zu verwerfen und den Kurs der Wirtschaftspolitik zu ändern - wie seinerzeit Roosevelt mit seinem New Deal. Im heutigen Europa müsste Deutschland ein solches Leadership zeigen - und versagt aus mehreren Gründen:
Erstens: In keinem anderen Land ist der marktreligiöse Dogmatismus der Ökonomen so ausgeprägt. Für sie war schon in den 1950er Jahren der "Ordoliberalismus" attraktiver als die Theorie von Keynes. Demnach braucht es nur einen staatlich gesetzten "Ordnungsrahmen" (abgeleitet aus der Theologie des Thomas von Aquin), den Rest besorgt der Wettbewerb.

Zweitens: Während die Eliten in anderen Ländern doppelbödig agieren - in den Sonntagsreden marktreligiös, unter der Woche interventionistisch - glauben sie in Deutschland an das, was sie sagen - das ist in einer Krise höchst gefährlich. Der intellektuelle Dogmatismus wird durch den emotionellen Wert des „Sich-selber-treu-Bleibens" gestützt.

Drittens: Die (relativ) gute Lage der deutschen Wirtschaft wird auf die neoliberalen „Strukturreformen“ wie Hartz IV zurückgeführt. Tatsächlich aber ist sie der Nachfrage jener Länder zu danken (China, Indien, Brasilien, etc.), die ihre Wirtschaft gerade nicht neoliberal-finanzkapitalistisch organisieren.

Viertens: Das seit der Wiedervereinigung wachsende Nationalgefühl, die Benennung der Griechen oder Türken als Schuldige durch volksdümmliche Medien und Autoren, die stammtischtaugliche Schlichtheit von Analogien wie jener der „Schwäbischen Hausfrau“, all dies ergibt einen Meinungsstrom, von dem sich Politiker gerade zu Wahlkampfzeiten treiben lassen. Zivilcourage und Leadership gegen den Mainstream haben in Deutschland (derzeit) keine Chance.

Der Weg in die Depression ist vorgezeichnet. Um dem entgegenzusteuern, bedarf es eines „New Deal“, dessen zentrale Komponenten sind: - Schaffung eines Europäischen Währungsfonds als Finanzierungsagentur der Euro-Staaten, welcher die Anleihezinsen unter der Wachstumsrate stabilisiert;

- Festlegung von Bandbreiten für die wichtigsten Wechselkurse;

- langfristige Stabilisierung des Preispfades der für den Klimawandel hauptverantwortlichen Rohstoffe, insbesondere von Erdöl;

- Einführung einer Steuer auf Finanztransaktionen auch im Alleingang einiger Euroländer.

Ziel dieser Maßnahmen: Das Profitstreben soll (wieder) die Turbinen der Realwirtschaft antreiben, statt auf den Finanzmärkten durchzudrehen. Des Weiteren sollte ein „New Deal“ jene sozialen und ökologischen Bedingungen verbessern, welche durch den Markt nicht (hinreichend) gewährleistet werden können. Dafür müssen die Vermögenden einen Beitrag leisten. Auch zu ihrem Vorteil.

STEPHAN SCHULMEISTER, Mag. Dr., ist Wirtschaftsforscher in Wien und Autor des Bandes "Mitten in der großen Krise - ein ,New Deal' für Europa" (2011). Arbeitsschwerpunkte: Finanzmärkte, Instabilität der Finanzwirtschaft und Rückwirkungen auf die Realwirtschaft.

stephan.schulmeister@wifo.ac.at 